\title{
La administración de digoxina cinco días a la semana no está avalada por dosajes plasmáticos de la droga
}

Gnocchi C, Mazzocchi 0, Yaryour C, y col. Digoxina: ¿tratamiento continuo o discontinuo? Medicina 1998; 58:271-276

\section{Objetivo}

Determinar si los niveles plasmáticos de digoxina son distintos en pacientes que reciben una dosis diaria los siete días de la semana, de aquellos que la suspenden dos días consecutivos.

\section{Estudio}

Ensayo clínico aleatorizado.

\section{Pacientes}

Se incluyeron 36 pacientes mayores de 16 años, internados en un servicio de clínica médica, con diagnóstico clínico o radiológico de insuficiencia cardíaca y ecocardiograma con disfunción sistólica de ventrículo izquierdo.

\section{Intervención}

Un grupo recibió digoxina en dosis ajustada a la depuración plasmática, con intervalos de $24 \mathrm{hs}$ (grupo continuo [GC]); el segundo grupo también la recibió con dosis ajustada, pero suspendiendo la medicación los días sábados y domingos (grupo discontinuo [GD]).

\section{Medición de resultados principales}

Se realizaron dos dosajes de digoxinemia en cada paciente luego de 20 días de haber ingresado al estudio. Uno de ellos se realizó un día lunes y el otro un día viernes.

\section{Resultados principales}

Las digoxinemias de los días viernes fueron similares en ambos grupos, con una media de $1.1 \pm 0.52 \mathrm{ug} / \mathrm{L}$ en el $G C$ y de $1.04 \pm 0.58$ $\mathrm{ug} / \mathrm{L}$ en el $\mathrm{GD}$. En cambio las digoxinemias del lunes fueron estadisticamente diferentes entre ambos grupos, de $1.06 \pm 0.55 \mathrm{ug} / \mathrm{L}$ en el $G C$ y $0.61 \pm 0.39 \mathrm{ug} / \mathrm{L}$ en el GD, esta última en rango subterapéutico. A su vez este último valor fue estadísticamente diferente del valor del viernes del GD.

\section{Conclusiones}

La suspensión de la dosis de digoxina durante dos días consecutivos a la semana origina niveles subterapéuticos de la droga.

\section{COMENTARIO}

La digoxina se utiliza desde hace más de doscientos años como 'tónico cardíaco' y son pocos los estudios bien diseñados que demuestran su efectividad. En Argentina es una práctica usual la administración de esta droga de lunes a viernes, suspendiendo los días sábados y domingos. El presente ensayo clínico pone en evidencia que esta práctica no está sustentada ni por los dosajes plasmáticos de la droga ni tampoco por los conocimientos de la farmacocinética de la digoxina que tiene una vida media de 36 a 48 horas cuando se administra por vía oral.

En este trabajo se utilizó un valor normal de digoxinemia de 0.8 a 2 $09 / \mathrm{L}$, mientras que en gran parte de los trabajos el límite inferior es $0.5 \mathrm{ug} / \mathrm{L}$ e incluso menor aún, con lo cual la media de las digoxinemilas de los días lunes en el GD no estaría en valores indiscutiblemente subterapéuticos. El análisis está puramente relacionado a las concentraciones de las drogas (resultado intermedio*), y no a resultados clínicos de mayor peso como mejoría clínica de.los pacientes, disminución del número de internaciones y menos aún la mortalidad. De todas formas esta última no sería un resultado apropiáto a evaluar, no sólo por que se necesitaría un gran número y se- guimiento de pacientes, sino porque el estudiol Digitalis Investigation Group1 ya demostró que no modifica la sobrevida en pacientes con insuficiencia cardíaca y ritmo sili al.

En nuestra experiencia sobre el uso de la di.joxina en 149 pacientes mayores de 65 años internados en un servicio de clínica médica, encontramos que un $30 \%$ de los pacientes tenían digoxinemias fuera del rango normal ( 0.5 a $2 \mathrm{ug} / \mathrm{L}$ ) al ingres al hospital. Un $57 \%$ de los pacientes recibían la droga con suspensión semanal durante dos días, y sus digoxinemias (reflejo de la posología ambulatoria) no mostraron diferencias en los valores de los distintos días de la semana. Esto podría indicar que en pacientes ambulatorios (en este estudio estaban internados y la adherencia al tratamiento era del 100\%) y considerando un mayor rango terapéutico que el utilizado en el presente estudio, las diferencias encontrada serían menores.

A pesar de esto, no hay evidencias en la literatura que sustenten la indicación del tratamiento discontínuo con digoxina y, a la luz de los resultados de estudios como éste, creemos recomendable abandonar dicha práctica, manteniendo un correcto ajuste de la dosis de acuerdo a la función renal.

*Ver Glosario

\section{Dr. Daniel Roubicek}

Hospital Privado de Comunidad. Mar del Plata, Buenos Aires, Argentina. 


\section{El montelukast es efectivo en el tratamiento del asma crónica}

Montelukast, a Once-Daily Leukotriene Receptor Antagonist, in the treatment of Chronic Asthma. A Multicenter, Randomized Double Blind Trial. Reiss T, Chervinsky P, Dockhorn R, et al. Arch. Intern. Med. 1998; 158:1213-1220

\section{Objetivo}

Determinar la efectividad clínica del montelukast sódico por via oral en pacientes mayores de 15 años con asma crónica.

\section{Diseño}

Se planificaron tres períodos; 1 ) dos semanas, simple ciego* con placebo, 2) doce semanas, doble ciego*, periodo de tratamiento activo, 3) tres semanas, doble ciego*, lavado con placebo.

\section{Lugar}

Estudio multicéntrico, realizado en 50 centros en los EE.UU.

\section{Pacientes}

Se incluyeron en el período 1 , pacientes de ambos sexos, no fumadores, $\geq 15$ años y por lo menos con un año de síntomas asmáticos recurrentes ó persistentes. Todos los pacientes usaban como tratamiento 32 agonistas inhalatorios de acción corta a demanda y hasta un $25 \%$ también corticoides inhalatorios. Los pacientes eran incluídos en el período 2, si durante por lo menos 2 de las 3 visitas en el período 1, tenían un volumen espiratorio forzado en el primer segundo (VEF1) entre el 50 y el $85 \%$ del predicho y un incremeto de por lo menos $15 \%$ del mismo luego de la inhalación de 32 agonistas. Además se requería que utilizaran durante el periodo 1 al menos un disparo de $\beta 2$, y tener síntomas relacionados al asma en una escala utilizada para tal efecto. Se excluía la utilización de otras drogas diferentes de las mencionadas para el tratamiento del asma. Los corticoides por vía oral eran permitidos por empeoramiento de síntomas asmáticos, pero si esto ocurría más de 2 veces en el período 2 y 3 ó una vez en el período 1, los pacientes eran excluidos del estudio.

\section{Intervención}

Se randomizaron 681 pacientes para recibir $10 \mathrm{mg}$. de montelukast por vía oral ó un placebo idéntico.

\section{Medición de resultados principales}

Resultados Primarios: Medición de VEF1, puntaje de escala diaria de síntomas asmáticos.

Resultados Secundarios: Medición de pico flujo espiratorio, uso diario de ß2 agonistas, empeoramiento nocturno, calidad de vida, cambios en el porcentaje de eosinófilos, porcentaje de crisis asmáticas y días con exacerbación de los síntomas, discontinuación del tratamiento por empeoramiento del asma y días de asma controlada.

\section{Resultados principales}

El análisis de los datos se hizo por intención de tratar*. Se encontró una mejoría estadísticamente significativa sobre la obstrucción de la vía aérea medida por VEF1 (diferencia del $8.9 \%$ a favor del montelukast [IC 95\% 6.8\% 11\%]. También hubo mejoría en el pico flujo en el grupo montelukast, así como en los síntomas relacionados con el asma. El grupo montelukast tuvo más días con asma controlada y menos exacerbaciones nocturnas. No se observó efecto rebote luego de discontinuar el tratamiento.

\section{Conclusiones}

El montelukast es efectivo en el manejo del asma crónica.

Fuente de financiamiento: Merck Research Laboratories, Rahway, New Jersey; Instituto Costarricense de Investigaciones Clínicas, San José, Costa Rica; Social Security General Hospital, Guatemala Coty, Guatemala; and Clínica Ricardo Palma, Lima, Perú.

\section{COMENTARIO}

Los leucotrienos son sustancias secretadas por células pro-inflamatorias (eosinófilos y mastocitos), que producen síntomas indistinguibles del asma, y de esta manera están vinculados con su patogénesis. En los últimos 25 años, los inhibidores de los leucotrienos fueron el primer grupo de drogas desarrolladas para el tratamiento del asma que, probados en ensayos clínicos controlados obtuvieron resultados alentadores.

El presente estudio muestra que el tratamiento con $10 \mathrm{mg}$. de montelukast por vía oral mejora el grado de obstrución bronquial, los sintomas de la enfermedad, las exacerbaciones y el número de eosinófilos en sangre periférica.

El montelukast podría mejorar la adherencia en relación con los fármacos inhalados y evitar los errores de técnica que acontecen con su uso. ${ }^{1} \mathrm{Sin}$ embargo, persisten algunas dudas que aún restan dilucidar: 1) El verdadero mecanismo de acción; estaría mediado por un efecto antiinflamatorio plausible de ser utilizado a largo plazo, un mecanismo broncodilatador (modificando los síntomas de la crisis), ó ambos. 2) La seguridad a largo plazo: si bien en este trabajo no se encontraron más efectos adversos que el placebo, estos se han descripto con otras drogas del mismo

\section{Dr. Femán Gonzalez Bemaldo de Quirós \\ Servicio de Clínica Medica. Hospital Italiano de Buenos Aires. \\ Dr. Fernando Planells \\ Neumonólogo Universitario.}

grupo (cefaleas, rash, dispepsia, faringitis y aumento de las transaminasas). ${ }^{2}$ 3) Insuficiente información que compare el tratamiento con modificadores de los leucotrienos versus el tratamiento estándar. ${ }^{3}$

Por ahora, la mayoría de los autores opina que el tratamiento del asma en mayores de 16 años debe seguir basándose en el uso de corticoides inhalatorios con el agregado de 32 agonistas y/o aminofilina según la necesidad. Si bien el montelukast mostró diferencias con el placebo, la forma de reportar los resultados en el presente trabajo no permite estimar fácilmente su impacto clínico. El uso de montelukast se plantearía para ${ }^{4}$ : a) Asmáticos leves a moderados que no respondan al tratamiento con corticoides inhalatorios.

b) Asmáticos moderados a severos que sufran efectos sistémicos por las altas dosis de corticoides inhalatorios.

c) Pacientes con limitaciones físicas para la terapia inhalatoria (luego de haber intentado con aerocámara).

El Instituto Nacional de Salud de EE.UU (NIH), tambiên los ha recomendado como alternativa para pacientes mayores de 12 años con asma leve persistente, y existen estudios que han demostrado su utilidad para el asma inducida por el ejercicio. ${ }^{5-6}$

Las dudas pendientes serán respondidas en los próximos años, lo que permitirá decidir si este nuevo grupo de drogas es más eficaz que el tratamiento actual del asma y en qué grupo de pacientes su uso resulta útil clínicamente.

\section{Referencias}

1. Hanania, N. Wittman, R. Kesten, et al. Medical's personnel knowledge and ability to use inhaled medication delivery systems. Chest 105: 111-116. 1994 2. Koroghi, H. Iwagoe, H Fujii. The effect of the leukotriene antagonist montelukast of moderate and severe persistent asthma continues more than one year. Am. J. Respir. Crit. Care Med.
155:A 976. 1997

3. Israel, Cohn E, Dube L. Effect of treatment with zileuton, a lipoxygenase inhibitor in

in patients with asthma: a randomized controlled trial. JAMA. 275: 931-936. 1996

4. Hoswitz, Mc Bill K, Busse W. The role of leukotriene modifiers in the treatment of

asthma. Am. J. Respir. Crit. Care Med. 157: 1363-71. 1998

5. National Institute of Health, National Heart, Lung and, Blood Institute. 1997 Highlights of the expert panel report II: Guidelines for the diagnosis and management of asthma. Nationall Institutes of health, Bethesa, MD.

6. Leff J, Busse W, Pearlman D. Montelukast a leukotriene receptor antagonist for the treatment of mild asthma and exercise induced bronchoconstriction. N Engl J Med 1998; $339: 147-52$ 